\title{
O amor no feminino: ocultamento e/ou revelação? ${ }^{1}$
}

\author{
Denise Ramalho Dantas de Araújo \\ Universidade Federal do Rio Grande do Norte
}

\begin{abstract}
Resumo
O objetivo deste artigo é discutir implicações do relacionamento amoroso ser ou não visível e compartilhado pelos parceiros amorosos, de uma forma livre e espontânea, com todos os grupos sociais a que pertencem, ou pelos quais circulam As histórias de vida amorosa de três mulheres paulistanas, coletadas em entrevistas, constituem o corpus da pesquisa. O trabalho teve uma abordagem qualitativa, enquadrando-se no enfoque compreensivo. A revelação da existência do relacionamento amoroso - a sua publicização - angaria ganhos psicológicos para a parceira amorosa que vão além dos efeitos de liberação da tensão do ocultamento é a tese defendida neste ensaio. A existência de um refluxo sobre o próprio relacionamento amoroso, parte integrante do processo de amadurecimento pessoal, é a conclusão principal do trabalho. Os discursos ainda desvelaram outras posições entre as entrevistadas: o que é mais significativamente apreendido como amor agrega, fundamentalmente, eros e philia; amor é comunicação; o humor e a brincadeira são essenciais no relacionamento amoroso significativo e isto requer uma atuação segundo o verdadeiro-self.
\end{abstract}

Palavras-chave: amor; relações homem-mulher; criatividade; donald woods winnicott

\begin{abstract}
The feminine love: secret and/or revealed? The aim of this article is to discuss implications of the loving relationship when it is or not visible and shared by the loving partners, in a free and spontaneous way, with all the social groups they belong to, or they socialize with. The love life stories of three women from the city of São Paulo, collected through interviews, make up the corpus of the research. The approach is qualitative and it fits into the comprehensive focus. The revelation of the existence of the loving relationship - when it becomes public - produces psychological benefits for the female loving partner that go beyond the effects of releasing the tensions of a secret relationship is the thesis defended in this essay. The existence of a reflection on the same loving relationship, integral part of the process of personal maturity, is the main conclusion of the article. The speeches also unveiled other postures among the interviewed people: what is more significantly understood as love involves, basically, eros and philia; love is communication; the sense of humor and playing are essential to a significant loving relationship and this requires acting according to the true self.
\end{abstract}

Key words: love; male-female relations; creativity; donald woods winnicott

A proposta da pesquisa $O$ amor no feminino: ocultamento e/ou revelação?, base do presente texto, caracterizou-se por não levar em consideração, de forma rígida, as fronteiras internas e nem também as fronteiras externas da Psicologia. Isto se vincula a uma forma pessoal de relação com o mundo em que predomina a atração pelas articulações, pelo movimento, pelo deslizamento entre a face e o verso dos fenômenos. Eis aí o fundamento da "dança interpolar", mais adiante apresentada como opção teórica para o trabalho.

O objeto de estudo - as vivências amorosas da mulher em relacionamento amoroso heterossexual não integrado à vida social como um todo - foi definido baseado nesses passos anteriores. A sua construção foi, também, resultante de uma confluência de fatores, entre os quais quero falar daquele momento intrigante do confronto das leituras dos livros de Milan Kundera (1985), A insustentável leveza do ser, e de Francesco Alberoni (1987), O erotismo, pois havia uma "inversão" curiosa: na fala da personagem feminina de Kundera, viver dentro da verdade requeria o secreto, o estar no âmbito do privado, e o viver dentro da verdade para o personagem masculino requeria o espaço público, a visibilidade; já Alberoni traz a fala da personagem feminina de Kundera para situar a questão do viver dentro da verdade como sendo do âmbito do privado, curiosamente, quando está a discorrer sobre o erotismo masculino. Se ele não situa 
propriamente a questão como sendo própria do homem e imprópria da mulher, é interessante perceber que vem à tona quando está se referindo ao erotismo masculino. E aquilo foi intrigante porque a leitura de Kundera provocara a sensação de que "algo estava fora do lugar" e a leitura de Alberoni trouxera, em seguida, a impressão de que aquilo havia sido recolocado no devido lugar.

Não integrado à vida social como um todo significa situações de vida em que o par amoroso não transita livremente por todos os espaços de vida social dos dois, por algum tipo de constrangimento ou pressão, seja porque os dois são casados e têm relacionamentos extraconjugais, seja porque um dos dois é solteiro e o outro casado, ou ainda, por uma situação estigmatizável qualquer por uma sociedade que impõe sanções ao tipo de relacionamento.

Assim, o caminho que se impôs foi entrevistar mulheres em busca de suas histórias de vida amorosa. A ida à realidade concreta continha uma demanda de pesquisa que exigia, sem dúvida, uma orientação básica. Tinha, também, uma pergunta de partida, que servia de diretriz inicial: “como o reflexo da não-integração dos espaços de vida, pública e privada, no seu sentimento de identidade enquanto parceira amorosa, atinge o relacionamento amoroso para a mulher”, passível de revisão sim, mas necessariamente existente para permitir o direcionamento para uma população que cobrisse o objeto de estudo já definido. No entanto, o que interessava trabalhar eram os achados com que me depararia, os discursos das entrevistadas.

Em função dessa pergunta de partida, configurou-se o perfil que, apresentado a pessoas conhecidas em São Paulo por ocasião da minha permanência ali no primeiro semestre de 1998, possibilitou a indicação de potenciais colaboradoras: mulheres, com qualquer estado civil à época, da chamada classe média, entre trinta e cinqüenta anos, aproximadamente, devendo ter (ou ter tido) experiência de relacionamento amoroso não integrado à sua vida social como um todo. Deste modo, cheguei, finalmente, às colaboradoras e entrevistei aquelas cujos discursos compõem o corpus desta pesquisa: Cristina, Márcia e Ana Lúcia ${ }^{2}$. Estes foram os casos que, realmente, se apresentaram pertinentes ao objeto de estudo eleito para pesquisa e isto fixou o limite do universo pesquisado.

Definido um objeto de estudo, todos sabemos que, a partir daí, há como decorrência uma escolha de metodologia. E, para o objeto de estudo que foi definido, o modo de investigação adotado foi o de estudos de caso entrelaçados. E estes foram levados adiante numa abordagem qualitativa, com um enfoque compreensivo, tendo a fenomenologia como metodologia de compreensão.

O que aqui está como tese defendida é a leitura feita dos discursos de Cristina, Márcia e Ana Lúcia. Se foi provocada por uma pergunta de partida que engendrou toda a formulação da pesquisa, esta já não dominava a cena nessa hora do debruçar sobre as narrativas de suas histórias de vida amorosa. Respeitando tais achados, desenvolvi a seguinte tese neste "ensaio"3: a revelação da existência do relacionamento amoroso - a sua publicização - angaria ganhos psicológicos para a parceira amorosa que vão além dos efeitos de liberação da tensão do ocultamento.

De formação plurifacetada, fiz referência logo no início à atração pelas articulações, pelo movimento, pelo deslizamento entre a face e o verso dos fenômenos. Quero estender um pouco isto agora para, de certa forma, explicitar e ficar mais claro o tipo de pensamento que me é característico quando lido com o fenômeno psicológico e o sentido que isto toma no trabalho. Uma fita de Moebius (fita que deve ser fechada em círculo e colada após uma torção em suas pontas e que se apresenta, por isso, sem começo nem fim, sem lado externo nem interno) que fosse preparada com os elementos conceituais de um pólo de um lado e os elementos conceituais do outro pólo no lado oposto da fita, antes de ser colada após a torção (por exemplo: de um lado, eu, singularidade, particular, descontinuidade, etc.; e do outro lado: outro, pluralidade, universal, continuidade, etc.) poderia exemplificar a forma do pensamento que lida com o deslizamento de um pólo mais individual do "eu" - experiências ônticas, self, identidade social, papéis sociais - para o seu pólo mais social “Cultura”, pois os conceitos são contrapostos no verso da fita de Moebius, que não tem verso...

Foi esse o movimento básico subjacente à composição de um referencial teórico de forma a permitir uma dança interpolar, em que o amor, considerado como uma construção singular e plural, é visitado por olhares não restritos à Psicologia e Psicanálise e, nessas disciplinas, é percorrido com o apoio de conceitos oriundos de bases diferentes, na medida em que funcionalmente eles não são correspondentes.

Continuando, de certa forma, a demonstrar um pouco mais esta questão da forma de pensar, quero também falar de um momento da pesquisa em que, lendo o capítulo intitulado “O escudo de Aquiles” em $O$ divã a passeio, de Fábio Herrmann (1992), deparei-me com conceitos que foram visualizados em imagens mentais.

Herrmann (1992) foi lido com o pensamento no par amoroso. Ele faz uma analogia entre a função defensiva da representação e o escudo de Aquiles. No caso, ele utiliza duas camadas em vez das cinco do escudo original, sendo o espaço entre as camadas preenchido pela crença, como uma liga a unir as camadas. Para ele, na unidade do ato representacional, a camada externa seria a representação do real - a realidade - e a camada interna seria a representação do desejo, a identidade. E, entre uma camada e outra, existiria uma liga que seria a crença. A imagem que me veio à mente foi de dois indivíduos que estivessem, de certa forma, em contato, em comunicação, e que tivessem a possibilidade deste contato, desta comunicação, pelo toque dos seus escudos representacionais, pelos seus "escudos de Aquiles". E o espaço da crença seria exatamente o espaço das trocas simbólicas - sem contágio - da realidade compartilhada, ou seja, de imersão no mundo das representações da cultura na qual eles estão inseridos e que compartilham. Então, a produção de sentidos seria possível no mundo humano, exatamente, pela relação. E, ao mesmo tempo, seria a própria produção de sentidos que caracterizaria este mundo como humano. 
Tal imagem foi, imediatamente, suplantada por uma nova que se diferenciava um pouco da primeira pela associação feita com a questão do espaço potencial de Winnicott (1975). A imagem já se apresentou, então, como uma figura em que os escudos tinham uma certa imersão aprofundada no outro a ponto de, além do contato se dar pela crença, haver uma área em que havia certa imersão de um no desejo do outro. Havia uma área que seria a área do desejo. No caso, surgiu a imagem trazida pela lembrança associada do conceito do espaço potencial de Winnicott, aquele espaço do lúdico, do não-representável, o espaço do ôntico, do não-simbolizável. E aí estava o espaço da possibilidade da ação criativa que permite a emergência da singularidade numa forma revolucionariamente nova. Ou seja, visualizei na mesma imagem mental forjada pela teorização de Herrmann, a proposta conceitual de Winnicott neste sentido do espaço potencial e isto reafirmou para mim o caminho de deslizamento entre conceitos.

Para analisar as narrativas de Cristina, Márcia e Ana Lúcia, em que havia expressões diversas dos seus "eus", relatos daquelas experiências sentidas como de difícil descrição e de outras em que existia a clareza da referência aos aspectos reguladores de conduta presentes nos papéis sociais, recorri a uma articulação de conceitos como se fossem a mácula da retina: eles atuavam no fundo do meu olhar.

Assim, o aspecto plural da construção do amor e o aspecto singular desta construção tiveram os apoios teóricos de Comte-Sponville (1997), com sua visão articulada das modalidades do amor, Eros, Philia e Ágape; Francesco Alberoni (1986; 1987), com sua análise do erotismo, masculino e feminino; André Lázaro (1996), com a apresentação das Eróticas do mundo antigo, do mundo medieval, do mundo moderno e do mundo contemporâneo; Denis de Rougemont (1988), com sua análise sobre a paixão e o casamento no mundo ocidental; e Jurandir Freire Costa (1999) com sua gramática do amor romântico. Foram leituras que me permitiram elaborar uma periodização do amor de forma a que o reflexo dessa dimensão sócio-histórica na subjetividade da experiência dos parceiros amorosos fosse melhor compreendida.

Como base, a posição adotada por André Comte-Sponville (1997), apresentando três definições de amor e as tomando de forma não excludente - "Haveria, pois, para resumir, para simplificar, três maneiras de amar, ou três tipos de amor, ou três gradações no amor: a carência (erôs), o regozijo (philia), a caridade (agapé)." (p. 310) - mostrou-se extremamente valiosa para compor o esquema explicativo do fenômeno amoroso por não dissociar a busca egoísta de completude (eros) do amor desinteressado (agapé) e também da amizade (philia).

Concebendo o amor como uma potencialidade opcional, de acordo com Costa (1999), vali-me dos conceitos de Winnicott, verdadeiro-self e falso-self, de forma a que fosse compreendido o relacionamento amoroso como uma das vivências possíveis no amadurecimento pessoal de alguém, quando carrega a renovação e criatividade, ou então sem este caráter, quando está obstacularizado por um falso-self hegemônico. Vali-me, ainda, da articulação do conceito de identidade social. A opção por um tratamento teórico sem rigidez não me fez esquecer o cuidado com antagonismos inconciliáveis, permitindo que o deslizamento entre self e identidade social viabilizasse a análise dos conteúdos mais dinâmicos das entrevistadas e dos elementos vivenciais mais voltados ao aprendizado social da conduta amorosa.

Dessa forma, cabe explicitar que, do ponto de vista do psicológico, o apoio teórico central foi dado por Winnicott (1975, 1989, 1990) com seus conceitos de verdadeiro-self / falso-self, criatividade, espaço potencial e comunicação. Em termos simplificados, o verdadeiro self é ação e o falso self, reação. Postulando que, para um desenvolvimento emocional saudável, é fundamental um fazer que brote do ser, ou seja, que haja a efusão do indivíduo no mundo através da realização de seu potencial de criatividade, Winnicott ressalta a necessidade de um ambiente suficientemente bom que favoreça tal processo. Sua concepção de sujeito intersubjetivo leva em conta, assim, a comunicação como pilar da condição existencial do indivíduo. O lugar por excelência do fazer criativo é a área intermediária, também denominada espaço potencial, em que a tensão internalidade/externalidade e também a tensão separação/união submetem-se à transição que esgarça os limites entre tais realidades através do brincar, do fazer. Em suma, é o verdadeiro-self em ação que cria a condição do sentir-se real e isto é que realmente constitui a vida.

Mas, foram utilizados também outros conceitos, articuladamente, com ênfase para o conceito de identidade social que vem da psicologia social através de Ciampa (1993), além da própria leitura feita de Herrmann (1992), que foi fundamental para a decisão de fazer o deslizamento entre conceitos.

E, além disso, não como parte do continente teórico configurado pela visão da construção plural e singular do amor, mas como um istmo teórico, foram utilizados - e com grande utilidade teórica - os conceitos de desacreditável e desacreditado de Goffmann (1988) que, com sua visão de antropologia social sobre o estigma, ajuda a dar conta dos aspectos fenomênicos do objeto de estudo. Desacreditado seria o estigmatizado que assume que a sua característica distintiva já é conhecida ou é imediatamente evidente e desacreditável seria o estigmatizado que assume que a sua característica distintiva não é nem conhecida pelos presentes e nem imediatamente perceptível por eles.

Com este continente teórico ${ }^{4}$, assim complementado por Goffmann (1988), houve o trabalho analítico e os estudos de caso entrelaçados foram organizados e, assim, os conceitos articulados analiticamente com os dados da realidade epistêmica permitiram que surgissem conteúdos que estão distribuídos segundo os títulos: a força da revelação no processo de amadurecimento pessoal; o amor no casamento: uma etapa do desenvolvimento do self; dividindo os espaços da vida: o amor fora do casamento; os espaços da vida sendo divididos: amando homens casados. 


\section{A força da revelação no processo de amadurecimento pessoal}

Os estudos de caso - Cristina, Márcia e Ana Lúcia - que se entrelaçam na análise, repousam na expressão das experiências de vida amorosa das três entrevistadas. Como acontece em situação de apresentação da história de vida, há um movimento, interno à própria narração, em que as pessoas que falam têm, no próprio ato da fala, uma experiência em que também o ouvinte está inserido: “... depois que a entrevista acaba, a gente sempre continua pensando, pensando, sempre lembra de mais alguma coisa." (06/SP LXXIX $\left.)_{4}\right)^{5}$, "acho que até por tudo que eu te falei - que ultimamente eu não tenho conseguido fazer reflexão nenhuma - acho que até fiz muito aqui com você...” (07/SP CIII $\left.{ }_{10}\right)$. E, chegado o momento da interpretação e explicação, estive, necessariamente, dirigida pelo que ouvi, por mais ricos que fossem os aportes teóricos que se agregaram em meu auxílio para a análise.

A tese desenvolvida neste ensaio requer que seja considerada a questão do amadurecimento pessoal que, em Winnicott, é vista como o problema de tornar-se si mesmo (Loparic, 1999), a ser considerada, basicamente, à luz dos conceitos de self-verdadeiro e falso-self. Os sentimentos, as formas de troca aninham-se mais fortemente nesse espaço da discussão. Mas, o eu, a deslizar do pólo mais individual para as determinações coletivas do psiquismo, arrasta o foco do self para a identidade social e vice-versa. Assim, é possível, ainda que reconhecendo ser este feito um vôo rasante, vincular a discussão do relacionamento amoroso às concepções de amor em jogo.

Finalmente, quero lembrar que o ocultamento e/ou revelação das relações extraconjugais presentes nas experiências de vida amorosa das entrevistadas é um aspecto que não pode ficar sob o prisma único do indivíduo, na medida em que são conseqüência das formas sociais e históricas de organização social.

Dando início à apresentação dos estudos de caso entrelaçados, é preciso fazer uma primeira observação relativa à diferença de situação vivida pelas colaboradoras. As duas entrevistadas, Cristina e Ana Lúcia, viveram relacionamentos extra-conjugais enquanto eram casadas, e a outra entrevistada, Márcia, solteira, viveu relacionamentos amorosos com homens casados. É marcante o contraste entre os dois tipos de situação com relação à existência ou não de tensão nas suas vidas, provocada pela potencial pressão e estigmatização social de tais posições.

Na realidade, é possível pensar Cristina e Ana Lúcia como desacreditáveis no sentido goffmanniano, na medida em que toda uma tensão foi acrescentada às suas vidas no cuidado e na evitação de vir a descoberto, para as pessoas do seu mundo social, o que estava acontecendo. Elas tinham, ao mesmo tempo que valorizavam os sentimentos e emoções que as ligavam aos seus parceiros, incorporado uma culpa de caráter individual por terem se envolvido em tal tipo de relacionamento. O manejo da situação incluía a dificuldade da contínua contradição entre o nível representacional e vivencial do que acontecia.
Cristina fala, espontaneamente, sobre a primeira vez em que a visibilidade fez parte de um relacionamento seu, após sua separação com o marido, a importância do ocorrido eloqüentemente expressada em termos prosódicos. A revelação do relacionamento amoroso extrapola em efeitos a anulação da tensão vivida pelo ocultamento. Para Cristina, não ocorre, simplesmente, um alívio por não ter que esconder o que vive pela eliminação da hipocrisia que a perturba, mas algo mais surge no âmbito da exposição pública, algo que se aproxima do sentimento de orgulho por estar visível com seu par. Assim, para a mulher na condição de desacreditável em função de um relacionamento amoroso clandestinamente vivido, poderiam estar em jogo muito mais coisas do que o drible da ameaça contínua de rejeição social pela conduta não aceita pela sociedade. Evitar tal conseqüência corresponderia ao ganho do ocultamento em si mesmo: não sofrer as sanções que adviriam da visibilidade. Entretanto, a não revelação implica também a perda dos ganhos da revelação. Quando o relacionamento pode acontecer também no espaço de vida pública, a revelação integra o processo de desenvolvimento pessoal da parceira amorosa. Em contrapartida, é possível pensar que o ocultamento concorra para o cerceamento do eu. Estas questões também compõem a fala de Márcia que, diferentemente das outras duas entrevistadas, não fazia nenhum esforço para ocultar seus relacionamentos e, assim, não vivia a tensão decorrente do ocultamento.

A ocupação da posição de desacreditável, apontada para as outras, não ocorre com Márcia, no meu entender, ainda que os relacionamentos amorosos com homens casados sejam complexos e não possam ir a público, como ela mesma afirma. E também não seria o caso de situá-la como desacreditada. A razão para deixá-la à margem desse enquadramento reside no fato de Márcia lidar com a ausência de uma culpa individual que a marcaria com um estigma. Não que ela também não esteja sujeita às sanções sociais previstas para quem vive em desacordo com o código dominante, mas há nela, além da inexistência de laços formais com um marido que a fizesse assumir um papel com direitos e deveres definidos claramente a tal respeito para uma sociedade que condena o adultério, a superação de representações negativas acerca da ocupação do espaço de amante na vida do homem. Na verdade, o seu parceiro amoroso ocupa uma posição de desacreditável não acompanhada, subjetivamente, por ela.

Não seria, portanto, atribuível somente à eliminação dos efeitos negativos do ocultamento o poder da revelação do relacionamento amoroso. E, atentando para tal peculiaridade, torna-se necessário para mim levantar outro descortino para a reflexão. Se o relacionamento amoroso tem seu locus essencial na privacidade - o que até o situa no pólo extremo da intimidade do continuum vida pública/vida privada, com seu caráter de secreto - a publicização da sua existência irá ao encontro do não falseamento de vida social da pessoa, a fazer parte de sua integridade psicológica, assentada na espontaneidade e liberdade de ser e fazer. E, tendo em vista a determinação histórica dos lugares diferenciados para a mulher e o homem na sociedade, é possível pensar que o 
peso que a questão adquire para o indivíduo esteja também sujeito à variabilidade desses determinantes.

\section{O amor no casamento: uma etapa do desenvolvi- mento do self}

Cristina, Márcia e Ana Lúcia viveram o amor em várias de suas faces. Pela complexa tarefa de sua definição, o que lembra o pensamento de Rabindranath Tagore, "amor é mistério sem fim: não existe o que explique”, tentarei dar conta do que as entrevistadas apreendem como sendo mais significativamente correspondente a amor no contexto do relacionamento entre um homem e uma mulher, sem deixar fora da análise outras modalidades não tão representativas, mas também experienciadas e significativas em termos de suas histórias de vida.

O amor é buscado primeiramente no casamento por Cristina e Ana Lúcia. Elas viveram a expectativa social de um projeto de vida modelar na nossa sociedade brasileira contemporânea para as mulheres: crescer e casar, cuidar da casa, do marido e dos filhos, como elementos-chave do papel de esposa e de mãe ${ }^{6}$. E cumpriram a seqüência de passos previstos em tais diretrizes de vida. O casamento teve, para ambas, uma função de prover de cuidado, até certo ponto, suficientemente bom, o seu novo espaço de vida, oferecendo um lugar de paz e tranqüilidade até um dado momento, diferente para cada uma delas, em que Cristina e Ana Lúcia transbordaram os limites então estreitos para os eus que cresceram - com a concorrência concomitante de processos terapêuticos realizados - ultrapassando as dimensões de tais contornos rígidos.

Cristina, embora tenha em pouco tempo se dado conta da sua própria insatisfação com o relacionamento, com forte desencontro na área sexual, encontrou no casamento o meio favorável para que a atuação sob o domínio do falso-self não fosse além da sua função defensiva, a garantir, de forma adiada, a possibilidade de emergência do verdadeiro-self. Ana Lúcia, por sua vez, teve um período longo em que o casamento atendia às suas necessidades. Durante a maior parte do tempo, viveu bem com o marido e na sua descrição fica clara a função do ambiente para uma recomposição do eu.

Se bem que o casamento forneça tais condições ambientais para Cristina e Ana Lúcia, isso não se deve a uma redefinição dos papéis sociais dos membros de uma família. A estruturação de direitos e deveres constituintes dos padrões das relações marido-esposa, mãe-filho(a), pai-filho(a), irmão-irmã, interiorizada por elas foi, provavelmente, muito semelhante àquela exemplar para seus pais. As representações sociais desses papéis, no entanto, integraram vivências diferentes que reposicionaram a ocupação dos lugares numa certa superação do ambiente familiar conturbado que aconteceu no caso de ambas as entrevistadas. A metamorfose ocorre mesmo sob o peso do instituído em papéis socialmente estabelecidos. É o self em movimento, na busca de uma vida que valha a pena. No ato representacional, as dimensões singular e plural articulamse também em termos do desejo e do real.

No casamento, vivido dentro de moldes conservadores por ambas, Cristina e Ana Lúcia seguem, elas e seus maridos, sob a égide do falso-self, mantido o movimento subterrâneo do desenvolvimento. Um amor que se aproxima de ágape para ambas, com lampejos de philia para a segunda. Será eros, no entanto, que forçará a entrada das duas na posição de desacreditável, mais adiante desse tempo em que o casamento ainda as acolhe suficientemente.

Como instituição, o casamento apresenta o amparo e o conforto de tudo aquilo que é aprovado socialmente. A sua representação contém elementos do amor romântico, arrastados no tempo, a partir do amor cortês. Muito criticada, mas mostrando-se de difícil superação, esta forma de ser atual do relacionamento homem-mulher contém grandes contradições. Se a força ideológica ainda sustenta, para muitos jovens, a visão idílica do casamento como o lugar do amor, as contradições afloram, em Cristina, no próprio discurso.

Ágape é protetor. A sensualidade sem espaço no casamento de Cristina, com sua vida sexual insatisfatória, de certa forma a protege de um possível medo de uma relação fusional antes de realmente assegurado seu senso de ser. Contudo, ágape é restritivo. A comunicação entre o casal não ultrapassa, quando existe, o nível da comunicação explícita, indireta ${ }^{7}$. Depois o silêncio. Dessa forma, chegaram ao fim os dois casamentos.

Assumir e concretizar o desejo da separação, como aconteceu tanto para Cristina quanto para Ana Lúcia, indicam mais um grau de amadurecimento no caminho que o self realiza da dependência para a independência, que as priva das vantagens secundárias como segurança e tranqüilidade que o casamento lhes assegurava enquanto funcionavam basicamente apoiadas nos seus falsos-selves. Por outro lado, o espaço público é requerido para ampliação do seu mundo, voltando as duas entrevistadas a situarem a vida profissional como elemento importante das suas identidades sociais, em consonância com o processo de desenvolvimento do self. Primeiro ser, depois fazer, pode ser lembrada como a seqüência de reestruturação do eu no casamento e efusão no mundo através da atividade profissional. A confiança advinda da capacidade de novas inserções no social supera a dificuldade da lacuna de proteção que havia nos casamentos. O cumprimento submisso do papel social de esposa fazia par com a imaturidade do self, agora sendo deixada para trás.

Não foi rapidamente que Cristina atingiu a condição de seguir sozinha.. Ainda houve um período, após sua decisão, em que esperou que o marido saísse de casa, o que não ocorreu.. Foi assim que ela resolveu, com todas as dificuldades, sair e consolidar a separação que já havia, efetivamente, dentro de casa. Para Ana Lúcia, num certo sentido, o caminho foi facilitado pelo marido, que saiu de casa. Porém, o ponto de inflexão decisivo para a separação aconteceu bem antes, com o enfrentamento daquele que ocupava o lugar do provedor, para poder trabalhar à noite, em função de uma oportunidade profissional importante para ela.

Havia tanto em Cristina quanto em Ana Lúcia uma ausência de admiração pelo marido. Ainda que vistos como boas pessoas, eles não gozavam de prestígio. Este elemento, a admiração, emerge como um fundamental fator concorrente 
para o apaixonamento que as levará a manterem relacionamentos extraconjugais, a significarem outro lugar do amor nas suas vidas. Agora Eros surge de mãos dadas com Philia e são outros os tipos de comunicação disponíveis para os parceiros amorosos, além da comunicação explícita, indireta: a comunicação intermediária, que existe na área cultural - e no amor - a partir do brinquedo, e a comunicação pessoal e silenciosa, não-verbal, que é sentida como real.

\section{Dividindo os espaços da vida: o amor fora do casamento}

A ausência de comunicação no casamento, em quaisquer de suas formas, mas, fundamentalmente, daquele tipo necessário a um existir para o outro, minou a possibilidade de reconstrução do relacionamento, tanto para Cristina, quanto para Ana Lúcia.

As entrevistadas encontraram o espaço em que viam o que não estava para ser visto em relacionamentos com amantes. De certa forma, ambas dizem o mesmo, com base em experiências diversas: ser verdadeira é poder se comunicar. A verdade no relacionamento reside na espontaneidade, na expressão de si, na comunicação de sentimentos, no compartilhar empaticamente as vivências de cada um e dos dois. Amor é comunicação.

Os fragmentos dos discursos das entrevistadas trazem uma especificidade importante para destacar o amor na acepção em uso, o amor entre um homem e uma mulher: a vivência da sexualidade plena. A comunicação que embasa a verdade no amor, apreensível no que dizem Cristina, Ana Lúcia (e também Márcia, como será visto a seguir) requer o toque de eros e de philia, e o apaixonamento com o sexo consumado - que integra o mito do amor-paixão profanado na atualidade - é parte da sua configuração. Esta é a figura mais representativa do que as entrevistadas apreendem como sendo mais significativamente correspondente a amor no contexto do relacionamento entre um homem e uma mulher e que encerra uma possibilidade de congruência de duas disponibilidades para a experiência de espaço potencial, a dos indivíduos que compõem o par amoroso a engendrarem um relacionamento em que o lúdico tem um lugar especial.

Isto não quer dizer que os relacionamentos com os amantes atingiram a condição de terem lado a lado selves maduros a comporem pares amorosos com a perfeição do quadro descrito. Tanto para Cristina quanto para Ana Lúcia, os amantes fizeram parte de uma fase de transição em suas vidas, em que estavam se estruturando como pessoas, lidando com dificuldades a serem vencidas em várias frentes, inclusive em relação aos próprios casamentos. Os falsos-selves estavam segurando a situação em equilíbrio instável, porém possível com o auxílio dos papéis sociais de esposa e dona de casa, enquanto os verdadeiros-selves ensaiavam vôos baixos ainda no horizonte enevoado de suas independências.

Neste contexto, por que o ocultamento da existência do relacionamento extraconjugal, mesmo aí, haveria de significar uma limitação a implicar uma certa perda pessoal? Vou caminhar junto com alguns elementos de vida das duas entrevistadas para tentar um maior esclarecimento da questão.
Em Cristina, há uma fala fortemente impregnada de imagens que põem o amor na posição idealizada da visão romântica, correspondendo ao início de suas experiências de vida amorosa. Em vários momentos, isto está presente, sendo, no entanto, perceptível uma gradual diminuição, ao longo do que pode ser interpretado como processo de amadurecimento do self.

Fortemente presa ainda a uma visão de mundo conservadora, absorvida principalmente em seu meio familiar, Cristina debate-se na árdua tarefa de desconstrução/ reconstrução de toda uma realidade de vida e sua representação. Mas, o seu falso-self garante-lhe, até mesmo o lidar melhor com sua culpa pelo relacionamento paralelo ao casamento, na medida em que sua conduta seguia aspectos valorizados do papel que interiorizara para ser mãe e esposa, integrante de sua identidade social.

Tal divisão, no entanto, traz-lhe dificuldades, na proporção em que há uma incipiente ocupação do espaço da espontaneidade em sua vida. O amante, a terapia - lugares em que há comunicação e constituição do espaço potencial situações lúdicas vivenciadas são novos elementos do mundo de Cristina. Ampliar isto é um desejo que cresce e que é difícil de poder se realizar na configuração existente.

Ao mesmo tempo, a permanência na situação de duplicidade de relacionamentos acarreta uma série de conflitos. Há fatores subjacentes que, existindo na fragmentação de vida em espaços sociais dissociados, a impulsionam para uma vida em que seja possível manter a continuidade entre tais espaços. Apresenta-se, para Cristina, a mesma inviabilidade antevista por Ana Lúcia. Esta, em certo momento de seu discurso, denota que a questão da verdade no relacionamento amoroso também se inclui nos componentes do desconforto psicológico gerado pela situação de ocultamento. De alguma forma, o relacionamento era percebido nos seus limites desde seu início, por ambas, mesmo havendo um grande encontro.

Os relacionamentos extraconjugais, levados em meio a conflitos, culpas e reparações, ocupavam, no âmbito dos anseios, um espaço a ser ampliado em suas vidas. Mas, como parte das contradições vividas, houve também o desejo de consolidar os laços nos próprios casamentos. Acreditar na mudança como condição potencial do ser humano estava nos discursos das entrevistadas e, provavelmente, isso ativava suas buscas pessoais em termos de amadurecimento do eu e de sentido de vida.

Apreendo tal crença como indício revelador de verdadeiros-selves, em Cristina e Ana Lúcia, com possibilidade de assumirem, cada dia mais, a direção do movimento de suas vidas. Assim, agiram ao longo das histórias de vida que narraram, mesmo atuando nas camisas-de-força dos seus falsos-selves. Desvelaram algumas das contradições em que estavam imersas, debateram-se nos conflitos, amaram e foram amadas, sem que parassem o curso do amadurecimento pessoal.

Cristina reconhecia que o casamento, que tinha realizado seu projeto de vida, lhe sonegava algo de muito valioso. E, de forma confusa, entrevê as normas sociais interiorizadas de 
forma bastante arraigada em si mesma, mesmo contrariandoas por outro lado. Também não foi sem dificuldades que Ana Lúcia empreendeu sua travessia de um período decisivo para o seu fazer, possibilitado por um senso de ser reafirmado. Mas, não se deixou ficar na inércia.

As entrevistadas em questão vivenciaram relacionamentos que as conduziram aos seus momentos atuais, enriquecidas pelas experiências vividas.

Nenhuma das formas anteriores de relacionamento amoroso está sendo adotada atualmente, o que fica de acordo com o sentido de processo já destacado quando me referi ao movimento do seus selves.

Na presenteidade de Ana Lúcia, não há nenhuma certeza, mas há confiança. Ela diz estar mais serena, otimista e de bem com a vida. Tem mantido um relacionamento com uma pessoa mais nova (brinca sobre estar descendo na escada da idade dos namorados, mas destaca que há nos mais novos um maior senso de humor, em geral, e isso a tem fascinado muito) por quem se sente muito atraída, mas que tem sido de convivência complicada. Fazendo uma certa reflexão retrospectiva, Ana Lúcia não parece estar na dependência de dar certo o namoro para viver bem.

No acompanhamento dos percursos das duas entrevistadas, em foco nesta parte, emerge claramente a necessidade da espontaneidade integrante do verdadeiroself em ação, a expressão íntegra de si para uma superação do falso-self dominante, que durante boa parte de suas vidas atuou como função defensiva (embora ponha no passado, quero frisar que nada deve ser tomado no sentido absoluto, ou seja, não estou afirmando estarem Cristina e Ana Lúcia totalmente amadurecidas psicologicamente, e sim, que há uma curva ascendente perfeitamente perceptível em suas histórias de vida). Estes elementos falam de uma configuração de ser em construção, que se choca com as limitações impostas pelo ocultamento de um relacionamento amoroso, com sua restrição forçada ao espaço daquilo que é secreto para o resto do mundo social.

\section{Os espaços da vida sendo divididos: amando homens casados}

O lugar do amor para Márcia sempre esteve fora do casamento e, embora tenha se relacionado com homens casados, de certa maneira, ficava subjetivamente fora do efeito do ocultamento que havia, ocasionado pela situação de vida do seu par. Como já comentei, não apreendi tensão no seu relato acerca do risco de que alguém viesse a tomar conhecimento do caso. Ela mantinha uma postura ética de respeito à necessidade do outro, sim. Mas, não era uma necessidade sua.

O seu percurso de vida amorosa integra uma história de vida cujo desenho é mais retilíneo do que foi comentado nos processos anteriormente citados. De certa forma, é apreensível um conjunto de valores que, se não fogem à coercitividade da realidade social objetiva, como, ademais, é esperado que ocorra, se apresenta menos tradicional do que aqueles para Cristina e Ana Lúcia, no início de suas vidas adultas. Se o ponto de partida de suas experiências amorosas tem tal característica, por outro lado, Márcia segue sua vida sem que a forma de viver o amor e de estar no mundo, neste âmbito, sofra muita alteração ao longo do tempo.

Ser amante, ao que parece, passou a integrar a representação de si mesma, debatendo-se Márcia entre a representação que tem desse papel e a representação que reconhece existir também sobre ele. Ela usa o pronome pessoal na primeira pessoa do plural quando fala, denotando, naquele momento, seu sentimento de pertença ao universo referido. E, ocupar tal localização social acarreta conclusões penosas.

Há uma afirmação da entrevistada que vai, aparentemente, de encontro a um aspecto da tese desenvolvida. Ela diz que o tipo dos relacionamentos não concorria para que tivesse seu amor pelos amantes diminuído. O seu discurso, porém, revela problemas de clareza para a própria entrevistada quanto à sua permanência prolongada em tais relacionamentos.

Além disso, trago o fato de a parte da análise feita sobre Márcia não se enquadrar na posição, quer do desacreditado, quer do desacreditável, como suporte para defender que não seja o ocultamento algo que tenha tão acentuado refluxo negativo sobre o relacionamento amoroso no seu caso. Se o efeito da revelação a atinge da mesma forma que às outras duas entrevistadas, o efeito do ocultamento distancia as vivências, em comparação, quanto aos seus aspectos negativos. E, muito provavelmente, por não ser vivido da mesma maneira. Márcia não senta na poltrona do desacreditável que lhe oferecem, por vezes. Tomando por referência o caso que explicitou, já citado, aproveitava dos momentos de exposição no sentido do que lhe proporcionavam o prestígio advindo de tal companhia, já que o relacionamento não era sem incursões naquela parte do espaço público em que somente encontravam estranhos.

Todavia, isso não fecha a questão, servindo como elemento para reflexões posteriores ao desenvolvimento desta pesquisa. Creio, no entanto, que não derruba a defesa de que a revelação age como força construtiva da consolidação de um relacionamento amoroso para a parceira amorosa. A segunda parte da afirmação que trata do refluxo do ocultamento sobre o próprio relacionamento amoroso é que fica a requerer mais elementos para sua análise. Mas é possível, também, pensar em relacionamentos amorosos que nem morrem nem tampouco se desenvolvem, que permanecem aprisionados num estado inercial, sujeitos à influência dessa restrição, entre outros fatores. Na história de Márcia, a assimetria existente em seus relacionamentos significativos com homens casados não é apontada como fator desestruturante, mas, ao mesmo tempo, paradoxalmente, os relacionamentos tornam-se insatisfatórios e a esperança acaba, mesmo que neles continue.

Indo à frente no acompanhamento do conteúdo das vivências de Márcia, como forma de pensar sobre os elementos que compõem, possivelmente, o lastro do que está analisado acima. O lidar com a própria solidão é uma tarefa que requer um percurso de amadurecimento pessoal que construa um self amadurecido. Entendo ser isto, inclusive, um pré-requisito para que o relacionamento se assente 
igualmente na alteridade e não apenas no caráter narcísico, ali presente também. Sem o caráter fusional de um relacionamento com selves imaturos, os rompimentos não acarretarão o sentimento de perda do sentido de vida, como é possível acontecer na situação de imaturidade. A capacidade para estar só pode ser, assim, uma preparação necessária para o estar (só) com o outro, na(s) in(ter)dependência(s).

Compreendo que as possibilidades das duas pessoas funcionarem no espaço potencial em uma relação de amor são da mesma ordem, na medida em que ele pressupõe a maturidade em termos de selves, base de uma mutualidade “entre pares". Evidentemente, não estou desconhecendo a distância entre a realidade abstrata, teórica, e a sua manifestação concreta, fenomênica, pois senão, nem teria sentido escrever uma tese sobre o amor, à proporção que haveria de negá-lo, por não existir possibilidade de o encontrar na realidade daquela forma. Mas, não é o caso. E são as experiências imperfeitas - com salpicos de perfeição - de todos nós que servem de base para a crença na sua existência.

É importante considerar outros elementos para que seja compreendida melhor a posição de Márcia na sua história de vida amorosa. O realce dado à dimensão lúdica do relacionamento amoroso realça em tom mais intenso o que foi dito pelas outras entrevistadas. Sendo muito interessante a relação que estabelece entre a questão da verdade, a brincadeira e a intimidade, reforçando e ampliando o que já foi discutido anteriormente com Cristina e Ana Lúcia, a entrevistada, ora em foco, frisa que esses aspectos acontecem somente nos bons relacionamentos.

A intimidade e a brincadeira superpõem-se, equivalendo ao momento da verdade para Márcia. Há, no entanto, uma sutil diferença quando fala da brincadeira, como elemento presente em todos os bons relacionamentos, e da intimidade que, na sua fala, surge como elemento presente de forma diferente no casamento e em relacionamentos ilícitos. No primeiro caso, diz haver um maior envolvimento que institui a verdadeira intimidade, enquanto no segundo considera haver momentos de intimidade.

Gilberto Safra (2000), ao apresentar a relação entre intimidade e processo maturacional, demarca o conceito de intimidade: "penso ser importante que o termo intimidade seja preservado para utilização nas situações em que a complexidade madura da relação com o outro se dá na área do privado”. E, ao falar sobre o tema, ressalta a existência do outro como outro, aspecto fundamental, a meu ver, na consideração do relacionamento amoroso criativo.

Fica evidente no discurso de Márcia que ser amante lhe trouxe positivas vivências em termos de amor, sendo, inicialmente, até mesmo uma posição carregada de fascínio. Mas, inegavelmente, está presente no seu discurso a expressão também de que os relacionamentos ficavam estreitados em limites que impediam o atendimento de suas necessidades afetivas. Ainda que ela julgasse que seria possível uma solução sem a separação do casal, há contradições que evidenciam a dificuldade de tal caminho.

Comte-Sponville (1997) faz-se lembrado, de novo, pela retomada da reflexão sobre o amor apresentar-se em três gradações: ágape, eros e philia. Pois, Márcia trouxe elementos de eros e philia quando se referiu aos seus relacionamentos significativos. E, no entanto, ainda havia necessidade de algo mais para que ela sentisse que existia para o outro. Ser cuidada surge representado no ser presenteada. Isto, que não lhe ocorria, seria uma forma de sentir que era percebida pelo outro nos seus desejos e na sua maneira de ser.

\section{Conclusão}

O amor no feminino: ocultamento e/ou revelação?, com a tese "a revelação da existência do relacionamento amoroso - a sua publicização - angaria ganhos psicológicos para a parceira amorosa que vão além dos efeitos de liberação da tensão do ocultamento" teve as seguintes conclusões, os seguintes achados, melhor dizendo.

O que é mais significativamente apreendido como amor agrega, fundamentalmente, eros e philia, ou seja, embora ágape também entrasse como uma modalidade importante na vida dessas mulheres, o amor que significativamente tomava este sentido para elas não podia dispensar a modalidade erótica e a da alegria da amizade.

Amor é comunicação; sentir-se verdadeira no relacionamento amoroso é estar em comunicação intermediária e pessoal e silenciosa no sentido winnicottiano. Esta é uma conclusão muito rica do ponto de vista do entendimento do processo amoroso, na medida em que traz a questão do lúdico e da comunicação, além da questão simbólica e representacional, realçando os seres singulares em contato através dos seus verdadeiros-selves.

O humor e a brincadeira são essenciais no relacionamento amoroso significativo e isto requer uma atuação segundo o verdadeiro-self. Também com bastante força isto vem apoiar a questão da criatividade no relacionamento na proporção em que o humor e a brincadeira são aliados dessa possibilidade de acrescentar o novo às ações e relações.

\section{Referências}

Alberoni, F. (1986). Enamoramento e amor. Rio de Janeiro: Rocco.

Alberoni, F. (1987). O erotismo. Rio de Janeiro: Rocco.

Ciampa, A. C. (1993). A Estória do Severino e a história da Severina: um ensaio de psicologia social ( $3^{\underline{a}}$ ed). São Paulo: Brasiliense.

Comte-Sponville, A. (1997). Pequeno tratado das grandes virtudes. São Paulo: Martins Fontes.

Costa, J. F. (1999). Sem fraude nem favor: estudos sobre o amor romântico ( $3^{\underline{a}}$ ed.). Rio de Janeiro: Rocco.

Goffmann, E. (1988). Estigma: notas sobre a manipulação da identidade deteriorada ( $4^{\underline{a}}$ ed.). Rio de Janeiro: Guanabara Koogan.

Herrmann, F. (1992). O divã a passeio: à procura da psicanálise onde não parece estar. São Paulo: Brasiliense.

Kundera, M. (1985). A insustentável leveza do ser. Rio de Janeiro: Nova Fronteira.

Lázaro, A. (1996). Amor: do mito ao mercado. Petrópolis: Vozes.

Loparic, Z. (1999). A teoria winnicottiana do amadurecimento pessoal. Infanto Revista de Neuropsiquiatria da Infância e Adolescência (ISCMSP, São 
Paulo), 7(supl.1), 1.

Rougemont, D. (1988). O amor e o ocidente. Rio de Janeiro: Guanabara.

Safra, G. (2000, outubro). Intimidade e processo maturacional. Comunicação apresentada no IX Encontro Latino Americano sobre o Pensamento de Winnicott, 20 a 22 de outubro, Rio de Janeiro, RJ.
Winnicott, D. W. (1975). O brincar \& a realidade. Rio de Janeiro: Imago. Winnicott, D. W. (1989). Tudo começa em casa. São Paulo: Martins Fontes. Winnicott, D. W. (1990). O ambiente e os processos de maturação: estudos sobre a teoria do desenvolvimento emocional ( $3^{\mathrm{a}}$ ed.). Porto Alegre: Artes Médicas.

1. Trata-se da apresentação dos aspectos centrais da discussão da tese de doutorado em Psicologia Clínica (IPUSP), O amor no feminino: ocultamento e/ou revelação?, defendida em 2001.

2. Nomes fictícios.

3. A idéia de que um ensaio também se constitui em produção válida nas ciências humanas permitiu que, sem esquecer as exigências próprias do tipo de trabalho desenvolvido, algumas de suas características - o espírito crítico, o livre-exame, a liberdade pessoal que encerra experiências, e o esforço constante pelo pensar original, necessariamente crítico (Moisés, 1978) -, tenham servido de orientação ao presente estudo. O uso do termo está restrito ao que já foi observado e por isso está sendo posto entre aspas.

4. Embora não possa deixar de reconhecer a existência de um vasto acervo de pesquisas sobre o amor, a maior parte dirigida para aspectos comportamentais e atitudinais, é verificada uma certa ausência do tema no mundo científico. Se é verdade, por exemplo, que foram obtidas 111 referências na PsycLIT (love; male/female; relations) para o período de janeiro/90-junho/96, também o é que, em 13.set.98, uma busca através da internet com o serviço da BIREME, utilizando a LILACS, detectou apenas 29 documentos em português (amor; relacionamento amoroso) para o período de 1980-1998 (texto de nota de rodapé constante da referida tese da autora)

5. Código utilizado para referência ao material das entrevistas conforme foram transcritas e editadas: $01=n^{\underline{0}}$ da entrevista; II = $\mathrm{n}^{-}$da página; ${ }_{4}=\mathrm{n}^{\mathrm{O}}$ da linha.

6. Não existe a intenção de negar o avanço no campo da profissionalização da mulher e da divisão de tarefas caseiras, apenas o reconhecimento de que ainda é interiorizada tal expectativa de forma hegemônica, mesmo quando a mulher exerce uma profissão. Em contrapartida, ainda há a presença da expectativa predominante de que o homem seja provedor em relação à família, em que pesem todas as mudanças havidas. Ou seja, como papéis institucionais, não há grandes mudanças na área.

7. Estou me baseando na apresentação de Winnicott (1990) dos três tipos de comunicação: a) a comunicação explícita, que é indireta e envolve a linguagem; b) a comunicação intermediária, que existe na área cultural, a partir do brinquedo; c) a comunicação pessoal e silenciosa, não-verbal, que é sentida como real.

Denise Ramalho Dantas de Araújo, doutora em Psicologia Clínica pela Universidade de São Paulo, é professora no departamento de Psicologia da Universidade Federal do Rio Grande do Norte. Endereço para correspondência: Rua dos Tororós, 857, apt. 501. CEP 59.054-550 - Natal, RN. Tel.: (84) 213-3927. E-mail: gerundio@uol.com.br 